\title{
The PBL Teaching Mode of Academic Ability and Vocational Skills Cultivation Jing ZHANG ${ }^{1,{ }^{*}}$ and Min-Jiao CHEN ${ }^{1,{ }^{*}}$ \\ ${ }^{1}$ College of Art and Design, University of Technology, ShaanXi, China \\ *Jing Zhang, Associate Professor, Email: jingzhang_84@126.com \\ *Min-Jiao Chen, Graduate Student, Email:371692002@qq.com
}

Keywords: PBL, Graduate students teaching, Ability training.

\begin{abstract}
The article analyzed the graduate students' cultivation of PBL. It was based on basis of the question guiding, students as the main body, the teacher to guide. Following the teaching principle with the accuracy, integrity, feasibility, effectiveness, innovative etc. At last, it was puts forward the elements of the question guiding teaching mode and the teaching process. It is purposed to cultivate the students' comprehensive ability for the teaching of higher quality goals.
\end{abstract}

\section{Introduction}

Problem-based Learning, referring to as "PBL", it is an experiential curricular pattern which makes the problem as the center, exchanges the role between teachers and students of experiential teaching the teaching of the course. It is a kind of operation mechanism model which organically combines and expand the proposed "research teaching method" and "case teaching". This graduate curriculum mode can give full play to the initiative of students, teachers' guidance, teaching interaction, the diversity of measures and the flexibility of method. It is also good for students' understanding of basic knowledge and the use of research methods, stimulating their learning enthusiasm and creativity [1]. This teaching way emphasizes the problem as a starting point, to analyze and solve problems as the theme or building the learning process, to improve the ability to analyze and solve problems for the purpose.

\section{The Advantages and Characteristics of the PBL}

\section{The Advantages of the PBL}

PBL teaching model attaches great importance to the students' inner feelings and experiences, making the teacher translate the role of lecture into a guider, organizer and explorer multiple roles. At the same time to make the students get rid of the traditional force-feeding teaching. From the traditional "teacher speak, students listen to" transition to put students in active problem in front, make its direct to face the problem and make "students" to be the core.

PBL teaching mode on the surface aims to effectively solve the "problem" to realize the course, the essence of which is to construct knowledge system in the goal with the qualities of openness and generativity. This teaching mode do not too much emphasis on the division of subject areas, but cross and fuse the knowledge under the background of the "problem". It emphasizes the study of experience, methods and interdisciplinary knowledge. Through the problems raised and reasoned by the students, as a result students can gradually form a good logical thinking ability and the image thinking ability. 


\section{The Characteristics of PBL}

Beginning with the "Problem". The "problem" is the starting point to carry out the PBL learning, also the beginning of a project. "Problem" is that students may face in their daily lives, which connect with the times spirit and social demand and can arouse and maintain students' interest in learning. "Problem" should be based on course content, reflecting the content and the goal of the course, creating a science problem related to the curriculum, interest and research direction, and be able to combine the new concept and principle of the original knowledge and cross disciplines. The learning is a process of foreseeing problems, founding problems and solving problems, it is purpose that it can train the students' ability to solve the problem, skills to cooperate with each other and develop the ability of lifelong learning.

Independent Study. In the PBL curriculum, the students are required to actively participate in the investigation, the research background and analyzing the feasibility. During the process, students need to motivate themselves and set learning goals, to study independently and to guide themselves. Thus, the learning has become a kind of autonomous and independent mode that strives to find something. The students' ability of autonomous learning is not only vital to solve the facing problems, but also the important content and purpose of PBL teaching. It is helpful to cultivate the students' ability of independent thinking, independent learning and practice ability. In learning, students apply the new constructed knowledge into the complex problem solving and students from dependent learners gradually transform into a participatory learners in learning.

The Team Cooperation. Solving question of PBL based on the complexity and openness of the "problem", starting the learning in groups that the students can share professional knowledge and discuss the way to deal with the difficulties encountered in the process of problem solving around the common problems. Complex problems often need to integrate the various disciplines of knowledge to solve the problem and to help students integrate and internalize internal knowledge and contribute to generate more relationship between the background of the existing knowledge and current information. This kind of cooperation can learn from each other, complement each other, help each other, improve the students' team consciousness, strengthen the communication with teacher and classmates. Consequently, form a close relationship between students and teachers, and cultivate the students' ability of interpersonal communication and cooperation ability.

Take the Student as the Center.PBL is a learner-centered teaching mode, the role of teacher first is to build an atmosphere, form an equal communication and mutual learning atmosphere between teachers and students, and at the same time providing safeguard for the smooth implementation of the PBL. The subjectivity of the students get full play in problem solving activities. Students need to form study groups, analyze the problems, collect information needed to solve the problem by autonomic learning, set problem solving plan and carry out the plan to solve the problem. In the whole learning process, students independently to deal with the confronted questions and contradictions. Teachers as the study guides of the students should pay more attention to guide the students' creativity of solving the problem to the right direction, and supervise, promote and manage the whole process.

\section{Breaking the limitation of Teaching Material and Time}

Graduate students already have a more solid professional knowledge and the ability to acquire knowledge through self-study. So the PBL teaching for the graduate students should get rid of restriction of the teaching material and the systemic knowledge. Moreover, problem solving 
process is complicated and unpredictable so that PBL can not accurately prescribed the teaching content and time. The teaching plan must be flexible. In the process of learning, students often need to collect and analysis data, independent thinking, investigation, interview, writing, communication, discussion etc. PBL teaching mode will break through the classroom space and time limit.[2]

\section{The Construction of PBL}

PBL teaching mode can be operated very strong, due to it is the guidance of new ideas of education. When the people summed up the basic process of teaching: it contains determining the learning objectives, creating problem situation, analyzing the problems, exploring solutions, displaying results and summarizing the formation of reflection[3].

The first phase: Firstly, the teacher explain the basic theory of PBL, the learning process, requirements, evaluation rules and the advantages of using this kind of teaching mode to the students in detail, making the students to have a whole understanding of PBL mode. Then teachers discuss the role, value and prospect of knowledge from the whole knowledge according to the course content, in order to inspire the students' enthusiasm in learning and provide macro architecture and information resources for the topic. Teachers also need to provide an overview of the basic concepts of curriculum content and use a large number of successful cases and enlighten students to explore problems from the whole understanding.

The second phase: Split the student into groups, collect data, research and then select the topic. Lenin had led a famous saying in the west: "Found that the problem is half to solve the problem.'"[4] A good PBL topics must be from real life and meaningful, whether the success of the selected topic directly decides if the research can continue to be carried out. Due to the national unified master members' complicated study background, team members should be made up of different majors. Multidisciplinary cross learning helps to cultivate the students' divergent thinking and innovative ability.

The third phase: The student explain the question of theory, the teachers summary and evaluate on it. According to the integrated information that students collected, the teacher select information of target to give some supplementary explanation and answering. Classroom teaching is forever the central part of the school, good teachers not only have a deeper understanding of knowledge explained, but also express it out with an accessible way for students to understand easily.[5] The basic concept of teachers around curriculum provides students with the basic knowledge structure and supports to preliminary construct the students' cognitive structure. Intensively explain and discuss the emerging problems, teachers assist the students to refine the construction of knowledge meaning and offers support for the students to discover and innovate the new knowledge.

The fourth phase: The of people each group presented topics in class and evaluated each other. The groups can exchange learning experience and the students are required to define and clarify the subject and the research significance in the phase and the teachers further to supple the knowledge. At the same time, the students and the teacher evaluate the significance of the research of the topic and the evaluation of the subjects. Due to the advanced of some of students' selection of subject, some new frontier technology has been introduced into the curriculum teaching, and which promotes the updating of the teaching content.

The fifth phase: Writing a literature review, the teachers give guidance in the classroom at the same time. This phase mainly trains the students' comprehensive ability to search and analyze 
the literature in order to lay the foundation for future research. The teachers are supposed to guide students to make full use of electronic information technology search tool, such as all kinds of the Chinese search tool to search the information on the net or directly access to a variety of online resources and online course ware; also can search literature in CNKI and other Chinese academic database. Even when it is necessary students can search related English information in the es database (ERIC).

The sixth phase: Analyzed the question and presented the plan of solutions to problems in class. When the teacher analyzing and discussing typical problem can strengthen the students' academic ability. The process of researching the problem around the topic is very the process learners actively construct their cognitive structure for solving problems. Therefore, it is conducive to cultivating graduate students take the initiative to explore and discover knowledge, it also enhance the attitude and ability to actively construct the learned knowledge meaning which making learners can fully show their own thinking process and emotional experience, systematically train the students to analyze and solve problems and cultivate abilities to work independently engaged in scientific research.

The seventh phase: Demonstrate results of study in class. This stage is performance of the combination of theory and practice, which the students is show the final result of the study and the content of studying and to explain the teachers and the other students. Showing results and discuss that it can be further promote the exchange of experience between teachers and students. But, it also can appear some new problems, that is further analysis and tutor come from teachers, so that this phase can make the students ability to get greater improvement. After the research and discussion, students are required to continue to modify the study report. This practice can make the final submitted research report quality be better.

The eighth phase: Write learning feedback, reflection and sum up experience. In the whole process, the character of teachers transform from initiator of knowledge into internal promoters. The concept group of the overall knowledge system originally is macro, rough and fuzzy for students. But with the deepening of the teaching process and study, the overall concept group gradually become meticulous, clear and correct. Some new problems can be found in the process of writing report, students revise the problems in the report in order to enhance the quality of the report and deepen the understanding of the standardization of academic report.

\section{Cultivating the Graduate Student Academic Ability and Professional Skills}

\section{Cultivating Graduate Students' Research Intuition and Insight}

Intuition and insight is the base of scientific research, the best way to cultivate students' scientific research ability is to let students "enlighten" in their practice and strong innovation atmosphere. In PBL teaching mode, the teacher plays the role that is no longer a pure knowledge initiator, no longer tell the students about the existing knowledge results directly, but to guide students to analyze and solve problems when students confronted with all kinds of practical problems. So the world's top universities are all research university, these schools build a strong study atmosphere to promote the students' scientific research's intuition and insight by combining the teaching and scientific research and expanding the number of graduate students. 


\section{Developing the High-Level Thinking, Preparing for Independent Research}

Graduate students is a reserve army of scientific research team, should have strong ability of scientific research step by step. The core of the scientific research ability is high-level thinking ability. PBL is a teaching activity which organized according the order of discovery and solve the problem. Students must find problems, defining the problem, analyzing problem, putting forward hypothesis, collecting data, verify the hypothesis during the learning process. Due to the complex of problem is real, open and there is no ready-made or the only answer, this requires students to be creative and have critical thinking. So, the PBL is conducive to the development of high-level students thinking ability. The graduate student's teaching must put the focus on cultivating the high-level thinking, so that can be good for the postgraduates developing the scientific research ability and the future independent scientific research work.

\section{Promote the Cooperation Ability, Make the Graduate Students to Become Effective Collaborator}

Teamwork is the most basic premise in the PBL teaching mode, students need to study with the team. Team members analyze and solve problems through discussion, at the same time, they have division of labor, they need to do an in-depth study on some issues respectively and collect information on various aspects applying to problem solving. This can not only make the students get to know each other, learn from each other, also can promote the development of students' team spirit. In the modern scientific research of today's society, many of the problems is more and more diversity and comprehensive and in need scientific research personnel of different areas and different levels work together to complete it. A high performance team, often is more important than the ability of each member. This requires each scientific research personnel have strong ability of communication and cooperation with others. Graduate students teaching should also actively develop the method for group cooperative learning, attach great importance to the development of the graduate student's team spirit and the ability to work with others.

\section{Conclusions}

To sum up, the PBL teaching model following the law of the graduate education, deepened the reform of the postgraduate course teaching mode and strengthen the graduate student centered teaching concept, provided a clear and operational teaching activities organizational processes. And it making classroom teaching to become a platform of exploring and communicating new ideas and new technology in a great part, making the graduate student work on exploratory learning activities related to its research direction and research interests at the beginning of the course learning phase, promote students clear research direction ${ }^{[6]}$ The nature and purpose of this way is adapted to graduate education, reflected in many aspects, such as it can improve and promote the students' cognitive learning, cooperative learning, content comprehend, self satisfaction with professional identity etc. Thus, it can be seen from it, the PBL education mode can not only enable students to learn the basic knowledge, but also to become a high level of social needs of research personnel.

\section{Acknowledgement}

This research was a graduate teaching reform project of Xi'an University of Technology. Design major talent training mode study guided by "Entrepreneurship to create more 
employment opportunities”. Project number: 301-252041501.

\section{References}

[1] Li-ping Wang, Jian Wang.. Journal of Shanxi university of finance and economics. 2006(4). 108-110

[2] Meng-cheng Zhao. Jiangsu Higher Education. 2003, (4). 68-71

[3] Zhen Ma. The PBL teaching mode and the application research of graduate students teaching in colleges and universities in our country [D]"in Chinese". Shandong normal university. 2011.

[4] Wen-xun Lin. Degree and postgraduate education. 2005, (3). 5-9

[5] Qing-shi Zhe. Degree and postgraduate education.2002, (4).1-3

[6] Li Yao. Degree and postgraduate education.2015.32-36 